Ege Tıp Dergisi / Ege Journal of Medicine 2021; 60 (1): 96-98

\title{
Bisiklet gidonuna bağlı abdominal duvar fıtı̆̆ı: Nadir görülen bir travmatik herni
}

\author{
Abdominal wall hernia related to bicycle-handlebar: A rare traumatic hernia \\ Ahmet Hikmet Şahin [ \\ Balıkesir Atatürk Şehir Hastanesi, Çocuk Cerrahisi Kliniği, Balıkesir, Türkiye
}

Öz

Bisiklet kullanımı çocuklar için eğlenceli ve özgürlük hissi yaratan bir araç olduğu kadar, yaşamı tehdit eden kazaların nedeni de olabilir. Bu yazıda bisiklet gidon yaralanması ile acil servise başvuran bir olgu sunulacaktır.

Bisikletten düşme öyküsü ile acil servise getirilen 11 yaşında erkek çocuğun muayenesinde, sağ alt kadranda şişlik ve batın derisinde gidon ucuna ait vurma izi saptandı. Tomografi batın duvarı hasarını doğruladı. Batın eksplorasyonunda; gidon izine uyan bölgede fasya ve kasların parçalandığı, batında serbest kan olduğu ve terminal ileum mezenterinde defekt oluştuğu görüldü. Mezenter, kas ve fasya defekti onarıldı. Olgu postoperatif üçüncü günde şifa ile taburcu edildi.

Gidon yaralanmalarında ilk bulgu cilt üzerindedir. Olgular batın içi organ hasarı ve ventral duvar hernisi açısından izlenmelidir. Güvenli bisiklet kullanımına ilişkin davranış geliştirici eğitimlerin yapılması bisiklet kaynaklı kazaları önlemede etkili olabilir.

Anahtar Sözcükler: Travmatik abdominal duvar hernisi, bisiklet, gidon, çocuk.

\section{ABSTRACT}

The bicycle is a fun vehicle for children and creates a sense of freedom. It can also be the cause of life-threatening injuries. In this article, a case brought to the emergency room due to bicycle handlebar injury and its management will be presented.

An 11-year-old boy was brought to the emergency room with a history of falling off the bicycle. When the child was examined, swelling in the right lower quadrant of the abdomen and a sign of hitting the handlebar on the abdominal skin were detected. Computed Tomography imaging confirmed abdominal wall damage. In the exploration of the abdomen, it was observed that the fascia and muscles of the abdominal wall were fragmented in the area of the handlebar mark, there was free blood in the abdomen and a defect in the terminal ileum mesentery. Mesentery, muscle and fascia defects were repaired. The case was discharged on the third postoperative day with full recovery.

The first finding in handlebar injuries is in the abdominal skin. Despite the skin findings, the cases should be followed up for intraabdominal organ damage and ventral wall hernia. Cycling-related accidents can be prevented by providing behavioral improvement trainings on safe cycling.

Keywords: Traumatic abdominal wall hernia, bicycle, handlebar, child.

\section{GiRiş}

Bisiklet, çocuklar için eğlenceli ve özgürlük hissi veren bir araçtır. Bisiklet kullanımına ilişkin davranışlar, yetişkinler ve çocuklarda farklılık gösterir. Çocuklar bisiklet kullanırken kurallara daha az uymaktadırlar, bu nedenle çocuklardaki bisiklet kazaları daha ciddi seyretmektedir $(1,2)$.
Bisiklet kazaları, genellikle 9-15 yaş arası erkek çocuklarda görülmektedir. Bisiklet kazalarının \%5-14'ü künt abdominal travma ile sağlık kuruluşlarına başvurmaktadır $(2,3)$. Bu yazıda bisiklet gidon yaralanmasına bağlı ventral abdominal duvar hernisi sunulmuştur.

Sorumlu yazar: Ahmet Hikmet Şahin

Balıkesir Atatürk Şehir Hastanesi, Çocuk Cerrahisi Kliniği,

Balıkesir, Türkiye

E-posta: drhikmet.sahin@gmail.com

Başvuru tarihi: 04.12.2020

Kabul tarihi: 07.02.2021 


\section{OLGU}

11 yaşında erkek çocuk, bisikletten düştükten yaklaşık üç saat sonra acil servise getirilmiştir. Fizik muayenesinde batın sağ alt kadranda şişlik ve ciltte bisiklet gidonu ucuna ait vurma izi (Şekil1a) saptanmıştır. Yapılan bilgisayarlı tomografi (BT) incelemesinde; abdominal duvar sağ alt kadranda fasya defekti geliştiği ve barsak kıvrımlarının cilt altına doğru herniye olduğu gözlenmiş olup, görüntünün ventral herniye benzediği rapor edilmiştir. Abdominal duvar anatomik yapısı ve BT görüntüsü Şekil1b'de sunulmuştur. Olgu, yoğun bakım izlemine alınmış, sıvı replasmanı uygulanmış ve tetkikler sonrasında abdominal eksplorasyona alınmıştır. Orta hat insizyonu ile yapılan eksplorasyonda; gidon izine uyan bölgede, periton, $m$. transversus abdominis, $m$. obliquus internus abdominis ve $\mathrm{m}$. obliquus externus abdominis apenörozları ve cilt altı yağ dokusunun parçalandığı ve ventral herniye benzer şekilde defektten barsakların cilt altına doğru yer değiştirdiği görülmüştür. Batında serbest kan ve terminal ileum mezenterinde defekt saptanmış (Şekil-1c), ancak intestinal perforasyon saptanmamıştır. Batın temizliği sonrası mezenter defekti ile gidon izine uyan kas ve fasya defekti onarılmıştır (Şekil-1d). Postoperatif birinci gün peroral beslenen olgu üçüncü günde şifa ile taburcu edilmiştir. Olgunun ailesinden yazılı onam alınmıştır.
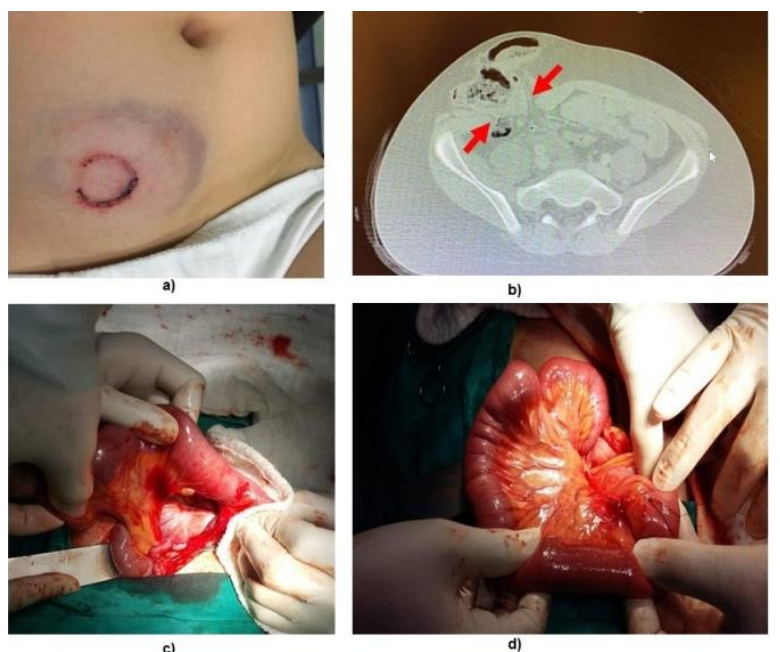

Şekil-1. Bisiklet gidonu. Bisiklet kazasında batın duvarında gidon izi (a), BT görüntüsü (b), terminal terminal ileum mezenter defekti (c) ve defekt onarımı (d).

\section{TARTIŞMA}

Abdomene yönelik bir travmada, genellikle önce derinin bütünlüğü bozulur. Travmanın şiddeti arttıkça deriden, intraabdominal organlara doğru yaralanmanın ağırığı ilerler. Ancak çocuklardaki bisiklet gidon kazalarında nadir de olsa, deri bütünlüğü bozulmadan intraabdominal organ hasarı gelişme intimali vardır.

Travma sonrasında abdominal duvarda şişlik görüldüğünde öncelikle hematom veya önceden var olan bir fitık akla gelir. Ancak önceden var olmayan bir şişlik olduğu anlaşılınca akla gelmesi gereken sorun, travmatik abdominal duvar fıtığıdır (TADF).

Travmatik abdominal duvar fıtığında en sık bildirilen (\%35) neden gidon kazalarıdır. Bunu ezilme (\%25) ve emniyet kemeri yaralanması (\%19) izlemektedir. TADF, karına ani, künt bir kuvvet uygulanması ile oluşmaktadır. Karın duvarına teğet olarak uygulanan travmatik kuvvetler, duvarın bütünlüğünü bozarak kaslara, fasyaya ve peritona bir kesme gerilimi iletir. Bu yapılardan en esnek olanı deri ise sağlam kalır ve ortaya çıkan defekt yoluyla abdominal organların deri altına fıtıklaşmasına neden olur $(6,7)$.

Gidon yaralanmaları, genellikle düşük hızda bisiklet kullanırken kontrolü kaybetme, ani fren yapmayla bisiklet ön tekeri ile gidonun 90 derece dönmesi ve abdomene sertçe batması ile gerçekleşir (3). Gidon yaralanmaları en fazla sol alt kadranda (\%32) görülmektedir (6). Genellikle abdomen derisinde kontüzyon, abrazyon veya hematomla sağlık kuruluşuna başvuru olmaktadır. Derideki görüntü ilk etapta dikkat çekici nitelikte olmasa da travmanın intraabdominal ciddi hasar oluşturma olasılığı gözden kaçırılmamalıdır (3-5, 8).

Çoklu travmalarda yaralanmanın şiddetini belirlemede, hastanın morbidite ve mortalitesinin tahmininde travma skorlama sistemleri kullanılmaktadır. Çocuklarda bisiklet kazaları dahil çoklu travmalarda kullanılmak üzere Pediatrik Travma Skoru geliştirilmiştir. Pediatrik Travma Skoru ile olgular -6 ile +12 arasında puanlanır ve tedavi önceliği belirlenir. Sekiz puanın altı, potansiyel olarak önemli bir travmayı ifade etmektedir (9). Bisiklet kazası ile gelen olgularda Pediatrik Travma Skoru genellikle 8-12 arasında hesaplanmaktadır (2).

Travmatik abdominal duvar hernilerinde esas olan primer onarımdır. Strangülasyon riski yok ise, cerrahi onarımının bir süre ertelenebileceği 
ve konservatif olarak izlenebileceği bildirilmiştir (3-5, 10).

Bisiklet kazalarında intraabdominal organlardaki yaralanma ve cerrahi prosedürün ağırlığına göre olguların hastanede kalma süresi 1-21 gün arasında değişmekle birlikte genellikle postoperatif birinci günde taburcu edilmektedirler (3$5)$.

Olgumuz literatürle uyumlu olarak; sağ alt kadranda şişlik ve ciltte bisiklet gidonu ucuna ait vurma izi ile acil servise başvurmuş, yaralanmanın oluş mekanizması incelendiğinde kontrol kaybı, gidonun dönüşü ve abdomene batması sonucu olduğu ve Pediatrik Travma Skorunun 12 olduğu saptanmıştır. Olgumuz postoperatif üçüncü günde şifa ile taburcu edilmiş, 6 ay sonraki kontrol muayenesinde, herhangi bir şikâyetinin olmadığı, ciltteki gidon vuruk izinin kaybolduğu ve yapılan USG incelemesinde onarım yapılan abdominal duvar yapılarında sorun olmadığı saptanmıştır.

\section{SONUÇ}

Bisiklet gidon yaralanmaları, düşük enerjili kazaya neden olmakta, ilk etapta cilt bulguları dikkati çekmektedir. Ancak ilk anda bulgu vermese de intraabdominal organ hasarı oluşma intimali nedeniyle, çocuklardaki gidon yaralanmaları ciddiye alınmalıdır. Özellikle, ventral herniyi andıran görüntü varlığında TADF akılda tutulmalıdır Erken tanı ve tedavi kadar önemli olan bir diğer konu da bisiklet kazalarının önlenmesidir. Bisiklet kazalarını önlemede koruyucuların kullanılması, güvenli bisiklet kullanımına ilişkin davranış geliştirici eğitimlerin yapılması, bisiklet yollarının yapılması, trafikte bisiklet kullananlara ilişkin risk yaratıcı davranışlardan kaçınmak gereklidir.

\section{Çıkar çatışması}

$\mathrm{Bu}$ yazının yazılmasında herhangi bir çıkar çatışması bulunmamaktadır.

\section{Kaynaklar}

1. Alkan M, Iskit SH, Soyupak S, Tuncer R, Okur H, Keskin E, et al. Severe Abdominal Trauma Involving Bicycle Handlebars in Children. Pediatr Emer Care.2012; (28): 357-60.

2. Çevik M, Boleken ME, Söğüt Ö, Gökdemir MT, Karakaş E. Abdominal injuries related to bicycle accidents in children. Pediatr Surg Int (2013) 29:459-463.2013; (29): 459-63.

3. Winston FK, Shaw KN, Kreshak AA, Schwarz DF, Gallagher PR, Cnaan A. Hidden Spears: Handlebars as Injury Hazards to Children. Pediatrics. 1998; 102 (3): 596-601.

4. Kiss K, Pótó Z, Pintér A, Sárközy S. Bicycle injuries in children: An analysis based on demographic density. Accident Analysis and Prevention. 2010; (42): 1566-9.

5. Nadler EP, Potoka DA, RN BLS, Morrison KE, BS, Ford HR. The High Morbidity Associated with Handlebar Injuries in Children. J Trauma. 2005; 58 (6): 1171-4.

6. Kumar A, Hazrah P, Bal S, Seth A, Parshad R. Traumatic abdominal wall hernia: A reappraisal. Hernia. 2004; 8: 277-80.

7. A GP, Dennis O. Autopenetrating Hernia: A Novel Form of Traumatic Abdominal Wall Hernia--Case Report and Review of the Literature. The Journal of Trauma: Injury, Infection, and Critical Care. 1996; 41: $1064-1066$.

8. Amoros E, Chiron M, Thélot B, Laumon B. The injury epidemiology of cyclists based on a road trauma registry. BMC Public Health. 2011; (11): 653-63.

9. İnan M, Ceylan T, Ayvaz S, Aksu B, Pul M. Pediatrik travma skorunun künt karın travmalarındaki tanısal değeri. Ulus Travma Dergisi. 2005; 238-42.

10. Liasis L, Tierris I, Lazarioti F, Clark CC, Papaconstantinou HT. Traumatic abdominal wall hernia: Is the treatment strategy a real problem? J Trauma Acute Care Surg. 2013; 74 (4): 1156-62. 